Boletín de la Sociedad Geológica Mexicana

VOLUMEN 64, NÚM. 1, 2012, P. 49-60

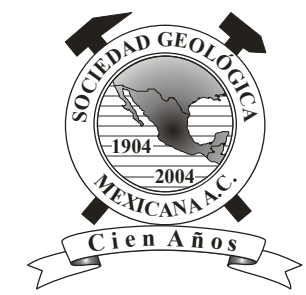

\title{
El intemperismo de calizas en monumentos prehispánicos mayas. EI caso de la cornisa del edificio 5N2, Río Bec
}

\author{
Luisa Straulino Mainou, ${ }^{1, *}$ \\ ${ }^{1}$ Centro Instituto Nacional de Antropología e Historia, Quintana Roo. Av. Insurgentes No. 974, Col. Forjadores, OTHON P. BLANCO \\ / QUINTANA ROO, CP 77025 \\ *azucarylimon@gmail.com
}

\begin{abstract}
Resumen
Se presenta el resultado de los análisis realizados en las calizas pertenecientes a una cornisa decorativa del edificio $5 \mathrm{~N} 2$ del grupo A de la zona arqueológica de Río Bec, con la finalidad de determinar las causas, mecanismos y efectos de deterioro que provoca el intemperismo en ellas. Estos procesos no han sido bien estudiados ni determinados para la zona del sureste de Campeche, región a la que pertenece la zona arqueológica de Río Bec. El conocimiento de estos mecanismos es necesario para la posterior conservación de los monumentos prehispánicos de la región. Las rocas de la cornisa presentaban estados de conservación disímiles por lo que se tomaron muestras de cada uno de los tipos de estado de disgregación identificados en campo. Estas muestras fueron analizadas por medio de láminas delgadas, microscopía electrónica de barrido y difracción de rayos X. Los resultados mostraron varios rasgos de intemperismo debidos principalmente a la acción de procesos químicos; entre los efectos más notorios estuvo la transformación de micrita en cristales aciculares. Estos efectos son similares a los que suceden en contextos edafológicos que presentan carbonatos de calcio relacionados con agua, materia orgánica en descomposición, hongos y raíces. La composición de las rocas en conjunción con el contexto de enterramiento y otros factores ambientales determinaron el estado de conservación disímil en las rocas de la cornisa.
\end{abstract}

Palabras clave: Roca caliza, intemperismo, disgregación, zona maya.

\begin{abstract}
The results of the analyses performed on the decorative cornice limestone of building 5N2 in group A at Rio Bec are presented, with the finality of determining the causes, mechanisms and effects that weathering promotes. These processes haven 't been well studied for the southeast of Campeche, the region in which the archeological zone of Rio Bec is located. Knowledge of these mechanisms is necessary for the subsequent conservation of the prehispanic buildings of the region. The stones of the cornice presented different conservation states; therefore, samples were taken from each of the disintegration states identified in field. These samples were studied in thin section, and by scanning electron microscopy and X ray diffraction. The results show many weathering features due to chemical processes; among the most notorious is the transformation of micrite to acicular crystals. These effects are similar to those that take place in edaphologic contexts that present calcium carbonates associated with water, decaying organic matter, fungus and roots. The composition of the rocks in conjunction with the archeological context and other environmental factors determined the different states of disaggregation found in the limestone of the cornice.
\end{abstract}

Keywords: Limestone, weathering, disaggregation, Mayan zone. 


\section{Introducción}

La roca fue, en la época prehispánica y hasta la aparición del cemento, un material ampliamente utilizado para la construcción de edificios o para el tallado de diferentes elementos decorativos. Por eso el estudio de estos materiales, el análisis de su intemperismo y la búsqueda de soluciones para disminuir su deterioro es de suma importancia para su preservación hacia el futuro.

La zona maya está enclavada en una plataforma de calizas, por ello esta civilización utilizó este tipo de piedra $\left(\mathrm{CaCO}_{3}\right)$ para como material constructivo; además, de ella se obtenían otros derivados como la cal, el polvo de piedra, etc. (García-Solís y Valencia-Pulido, 1997). Las soberbias construcciones presentes en la zona arqueológica de Río Bec, ubicada al sureste del estado de Campeche (Figura 1), que permanecen como vestigios del pasado maya, son un ejemplo del uso de estos materiales: están construidos con caliza obtenida de canteras locales y estaban revestidos de aplanados de cal y decoraciones de estuco (Arnauld et al., 2008).

La formación geológica sobre las que se asienta Río Bec es la Formación Xpuhil y se encuentra cercana a afloramientos de la Formación Icaiché. La Formación Xpujil está constituida por secuencias de caliza microcristalina, de textura mudstone, estratificada, con cambios de facies hacia limos y lutitas, así como depósitos de anhidrita y yeso con horizontes arcillosos escasos e intercalaciones de caliza hacia la parte superior de la unidad. La Formación Icaiché está formada por una secuencia de caliza estratificada y ocasionalmente masiva, de textura mudstone con raros fragmentos de sílice coloidal, y algunos cambios de facies hacia limos y arcillas; presenta también halita en su composición (Castro-Mora, 2002).

Las calizas de esta zona arqueológica presentan un severo deterioro (Michelet et al., 2007, 2008 y 2009) у diversas fuentes de información indican que la problemática de disgregación de la roca (Figura 2 a y 2 b) se extiende a las zonas arqueológicas aledañas que forman parte de la región estilística conocida como Río Bec. Se ha reportado esta grave problemática en informes e investigaciones de algunas zonas arqueológicas aledañas a la región, situadas en el sur de Campeche y Quintana Roo, tales como Chicanná, Kohunlich y Dzibanche, (García-Solís y Valencia-Pulido, 1996, 1997; García-Vierna et al, 1997; Anrubio-Vega, 1998). De hecho, dichos sitios arqueológicos han servido como casos de estudio para investigaciones en materia de conservación arqueológica que se han enfocado al problema de deterioro de la caliza y sus posibles soluciones.

Dado que las causas y mecanismos de alteración de las calizas no son bien conocidos en esta región maya, existe la necesidad de encontrar las causas, agentes y procesos de

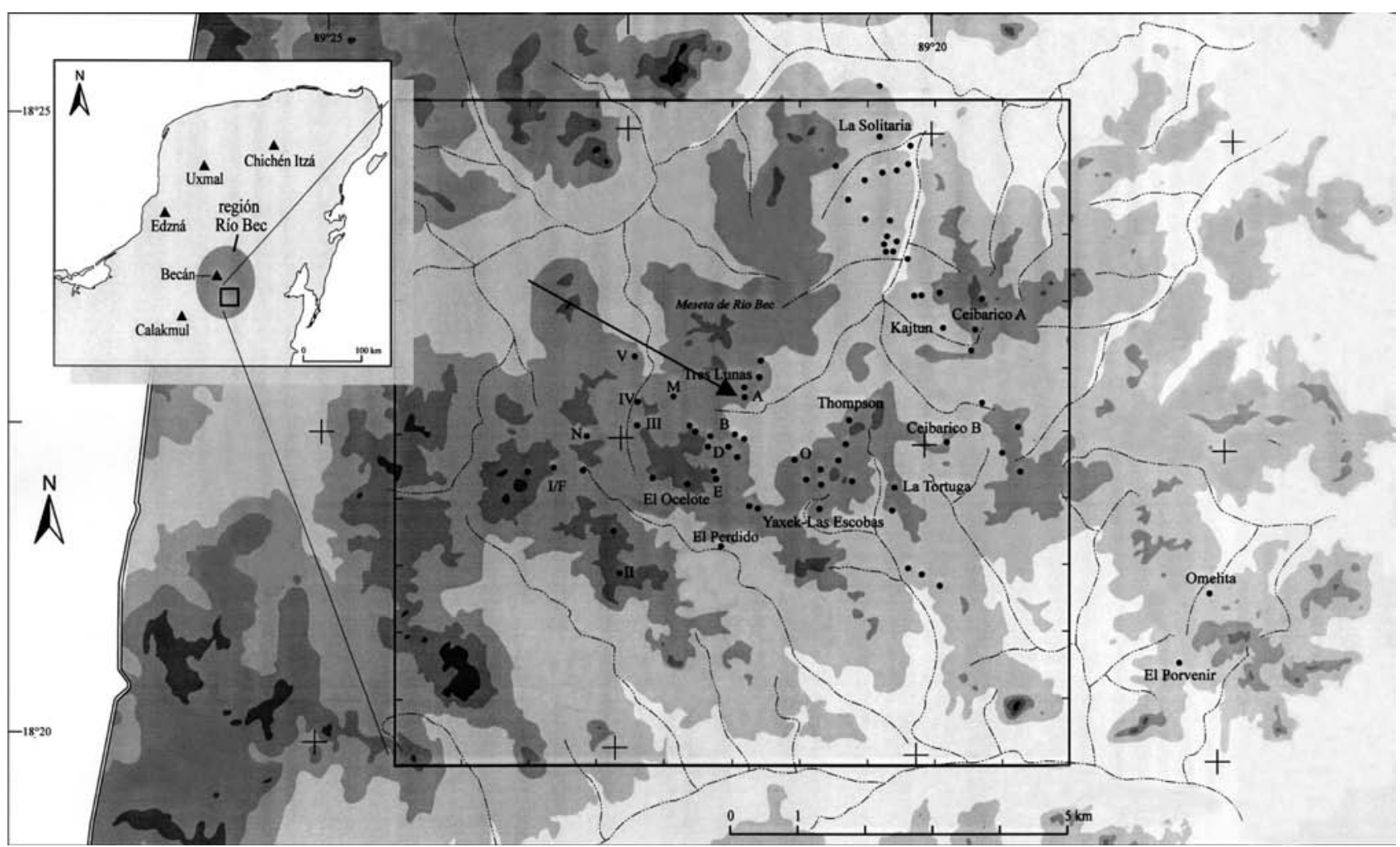

Figura1. Localización de la zona arqueológica de Río Bec. Se señala con una flecha la ubicación del grupo A al que pertenece el edificio $5 \mathrm{~N} 2$ y la cornisa. Las áreas marcadas con un punto corresponden a grupos de edificios en la zona arqueológica mientras que los números romanos y letras corresponden a los nombres de dichos grupos. Mapa proporcionado por el Proyecto Río Bec. Digitalizado por Dr. Philippe Nondédéo. 


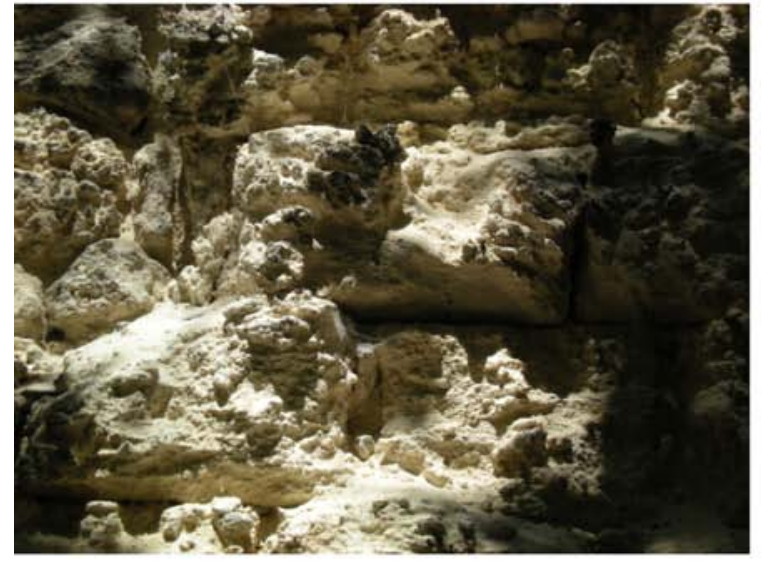

$50 \mathrm{~cm}$

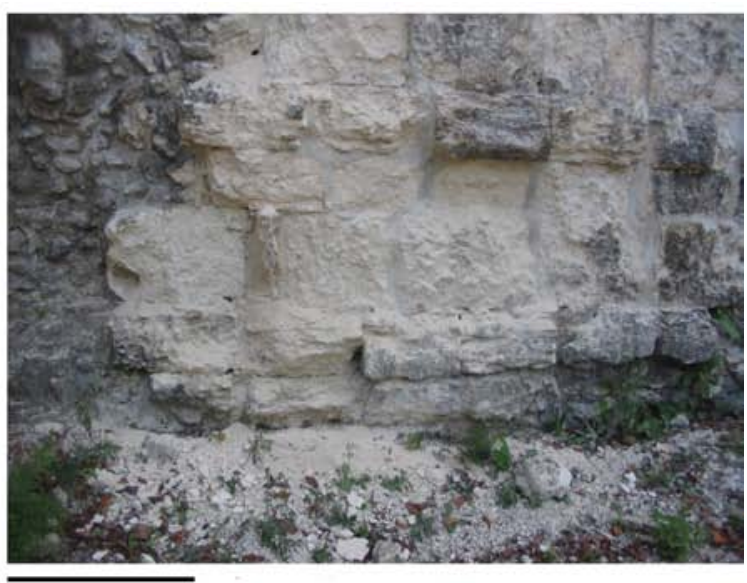

$50 \mathrm{~cm}$

Figura 2. Estado de conservación común de las rocas en edificios de la región Río Bec. a) Fachada norte del Edificio 6N2, zona arqueológica de Río Bec, 2009. b) Fachada oeste del edificio 6N2.

deterioro que las degradan para poder proponer una solución viable para su conservación. Es por ello que en este trabajo se presenta el resultado de los análisis realizados en las calizas pertenecientes a una cornisa decorativa del edificio $5 \mathrm{~N} 2$ del grupo A de la zona arqueológica de Río Bec, con la finalidad de determinar las causas, mecanismos y efectos de deterioro que provoca el intemperismo en ellas.

\subsection{Intemperismo en calizas}

Las calizas están formadas principalmente por calcita $\left(\mathrm{CaCO}_{3}\right)$ donde los aniones $\left(\mathrm{CO}_{2}^{-3}\right)$ se encuentran en capas intercaladas con cationes de calcio $\left(\mathrm{Ca}^{2+}\right)$. El mecanismo común de todos los procesos asociados al intemperismo físico es la generación de suficiente estrés en la roca ocasionando su fractura. Si la roca se rompe paralela a los planos de fractura, se formaran bloques o láminas; mientras que si las líneas de debilidad se encuentran en las uniones de los minerales, se formarán materiales determinados por el tamaño de grano de la roca original. No obstante, se pueden obtener tamaños más pequeños si los minerales son cortados transversalmente por microfisuras. En general el intemperismo físico provoca, grietas, fracturas, fisuras, disgregación, alveolización, desprendimientos entre otros efectos de deterioro (Vergès-Belmin, 2008).

Adicionalmente, cada una de las rocas que forman parte de un edificio posee una función determinada dentro del conjunto y, por ello, está sujeta a tensiones y compresiones estructurales por la posición en que se encuentra. La localización de la roca en el edificio será, por lo tanto, un factor que determine cómo y en qué medida afectan los agentes de deterioro y sus mecanismos.

Por otro lado, la disolución del carbonato de calcio es la principal causa de intemperismo químico en las calizas. Siguiendo a Ford y Williams (2007) la solubilidad de la calcita por disociación en agua pura y desionizada es muy baja; tanto, que es sólo un poco mayor que la del cuarzo. Sin embargo, se ha establecido que la alta solubilidad de los minerales carbonatados ocurre durante la hidratación del $\mathrm{CO}_{2}$ atmosférico, el gas más soluble de todos los gases estándares de la atmósfera, que produce ácido carbónico. Éste se disocia para formar $\mathrm{H}^{+}$siguiendo la reacción $\mathrm{CO}_{2 \text { (aq) }}+\mathrm{H}_{2} \mathrm{O} \leftrightarrow \mathrm{H}_{2} \mathrm{CO}_{3}$ (ácido carbónico); otros ácidos pueden aumentar la cantidad de este ion al igual que los efectos acomplejantes pueden incrementar la solubilidad de estos minerales. El ácido carbónico puede disociarse para formar $\mathrm{H}^{+}$y un ion bicarbonato $\left(\mathrm{HCO}_{3}^{-}\right)$el cual, puede a su vez volverse a disociar para formar un protón y un ion carbonato $\left(\mathrm{CO}_{3}^{2-}\right)$.

Toda el agua expuesta a la atmósfera ordinaria contendrá estas diferentes especies de carbono inorgánico disuelto, sea que haya o no rocas carbonatadas en el manto acuífero. $\mathrm{El} \mathrm{pH}$ del agua en calizas cae en el rango de 6.5 y 8.9. En este intervalo, el bicarbonato $\left(\mathrm{HCO}_{3}\right)$ es la especie predominante, mientras que el $\mathrm{CO}_{3}^{2-}{ }_{\text {(aq) }}$ es poco relevante debajo del $\mathrm{pH}$ de 8.3. El carbonato de calcio, a su vez, se disocia en el agua formando iones de calcio $\left(\mathrm{Ca}^{2+}\right)$ e iones carbonato $\left(\mathrm{CO}_{3}^{2-}\right)$. Cuando el carbonato reacciona en algún medio ácido se verifica la siguiente reacción: $\mathrm{CaCO}_{3(\mathrm{~s})}+\mathrm{H}^{+}$ $\leftrightarrow \mathrm{Ca}^{2+}+\mathrm{HCO}_{3}^{-}$. La reacción de disolución del carbonato de calcio en agua acidificada por anhídrido carbónico se resume de la siguiente manera: $\mathrm{CaCO}_{3}+\mathrm{CO}_{2}+\mathrm{H}_{2} \mathrm{O} \leftrightarrow$ $\mathrm{Ca}^{2+}+2 \mathrm{HCO}_{3}^{-}$.

Bravo-Álvarez et al. (2003) reportan una recesión superficial de la caliza a causa de la disolución procedente del agua de lluvia (probado en laboratorio) de entre 4 y 5 $\mu \mathrm{m}$ en un año; sin embargo, hay otros investigadores como Baedeker et al. (citado en Bravo-Álvarez et al., 2003) que hicieron pruebas in situ con agua de lluvia, que reportan el rasgo de recesión entre 6.7 y $9.0 \mu \mathrm{m}$ por año.

No obstante, cabe mencionar que el $\mathrm{CO}_{2}$ del suelo es la fuente más importante para la alta solubilidad de las 
rocas carbonatadas. La concentración de $\mathrm{CO}_{2}$ en los suelos se incrementa por la respiración de plantas, fauna del suelo, microfauna y microflora, principalmente bacterias, actinomicetos y hongos. Estos organismos además de incrementar la cantidad de $\mathrm{CO}_{2}$ producen una serie de ácidos orgánicos y agentes quelantes que incrementan la disolución de los carbonatos.

\subsection{Procesos de transformación micromorfológica en las} calizas

Los procesos de karstificación tienen como mecanismo principal la disolución de la caliza y su posterior recristalización, los cuales traen como consecuencia una serie de efectos macroscópicos en las rocas. Según Khokhlova et al. (2001), estos fenómenos de disolución y recristalización son la causa del cambio de tamaño, forma y fábrica de nódulos carbonatados en suelos. Este proceso se da de igual manera en las rocas carbonatadas, donde la matriz de cristales micríticos se transforma en cristales aciculares por disolución y recristalización de los carbonatos. Además de estos "pseudomicelios" se pueden encontrar también áreas impregnadas con carbonatos secundarios o películas delgadas, rasgos que son típicos de ambientes húmedos.

El patrimonio cultural construido con caliza no está eximido de sufrir este tipo de procesos debidos a la disolución parcial o selectiva de las superficies calcáreas, aunque se producen en menor escala (microkarst) (VergèsBelmin, 2008). Generalmente se observan efectos tales como una red de depresiones pequeñas interconectadas de escala milimétrica o centimétrica. Dicha pérdida de material afecta la estabilidad del conjunto general, mientras que la depositación de carbonatos recristalizados posteriormente puede generar otros problemas como disgregación o pulverización de la superficie causada por la recristalización de la calcita en nuevas formas cristalinas originando cambios micromorfológicos en la roca.

El carbonato de calcio con una apariencia pulverulenta está conformado principalmente por cristales aciculares con planos dentados. La posición de estas capas pulverulentas corresponde al paso de las raíces una vez que los suelos o las rocas fueron sepultados (Becze-Deák et al., 1997). La morfología de las agujas indica biomineralización provocada por hongos, lo que probablemente se asocie a materia orgánica en descomposición. Las placas dentadas o serradas de las agujas se han interpretado como precipitaciones secundarias físico- químicas, las cuales indican condiciones ambientales más secas.

Estos carbonatos secundarios pueden formarse en periodos muy cortos, variando de 1 hasta 47 días, por lo que son buenos indicadores de cambios en el ambiente.

Aunque es evidente la relación que hay entre la colonización biológica en las calizas y los efectos de formación de calcita secundaria, las referencias en cuanto al biodeterioro de las calizas pertenecientes a edificios prehispánicos, inclusive de la zona maya, hacen referencia a estudios microbiológicos de los organismos que los colonizan o al proceso de interacción entre las rocas y los organismos colonizadores (Gaylarde et al., 2001; Videla y Guiawet, 2001; De los Ríos y Ascaso, 2005; McNamara et al., 2005, 2006; De los Ríos et al., 2009). No obstante, hay muy poca información sobre los resultados micromorfológicos y mineralógicos de esta interacción. Un ejemplo de ello es el trabajo de Ostrumov et al. (2003) quienes estudian los cambios mineralógicos y micromorfológicos de la catedral de Michoacán, aunque las rocas utilizadas son de naturaleza distinta por lo que los datos y las interpretaciones no son extrapolables ni comparables, aunque la metodología y análisis hayan sido semejantes.

\section{Materiales y métodos}

La cornisa del edificio 5N2 (Figura 3) de la zona arqueológica de Río Bec está constituida por 77 piezas de caliza esculpida y decorada con estuco. Estas rocas se encontraron en el nivel de destrucción del edificio, bajo una capa de suelo enriquecida en humus (Figura 4) (Michelet et al., 2005, 2006).

Para este estudio se hicieron observaciones macroscópicas de las rocas y se llevaron a cabo estudios de micromorfología. Para estos últimos análisis se utilizaron fragmentos de algunas piezas ya que, al ser patrimonio cultural, las muestras deben ser limitadas porque la preservación es la prioridad.

La extracción de las muestras se realizó de dos maneras:

1. Recolección del material de deshecho de las rocas de la cornisa en los casos de piedras disgregadas para no afectar más la estructura de las rocas alteradas.

2. Percusión, mediante el uso de cinceles para rocas sin problemas o con disgregación moderada.

\subsection{Observación macroscópica en campo}

Durante los procesos de conservación y restauración fue posible observar de manera detallada las características y rasgos tanto primarios como secundarios de cada piedra de la cornisa. Estos detalles fueron cuidadosamente vaciados en fichas clínicas lo que permitió clasificar tres grupos principales de roca según su estado de conservación: muy disgregada, disgregada y no disgregada. También se pudieron observar detalladamente los efectos de intemperismo presentes a nivel macroscópico.

\subsection{Análisis de laboratorio}

Se realizaron láminas delgadas impregnadas con resina Cristal MC-40 para su estudio micromorfológico bajo el microscopio petrográfico con la finalidad de conocer la estructura original de las rocas y consecuentemente los procesos y efectos de intemperismo presentes a 

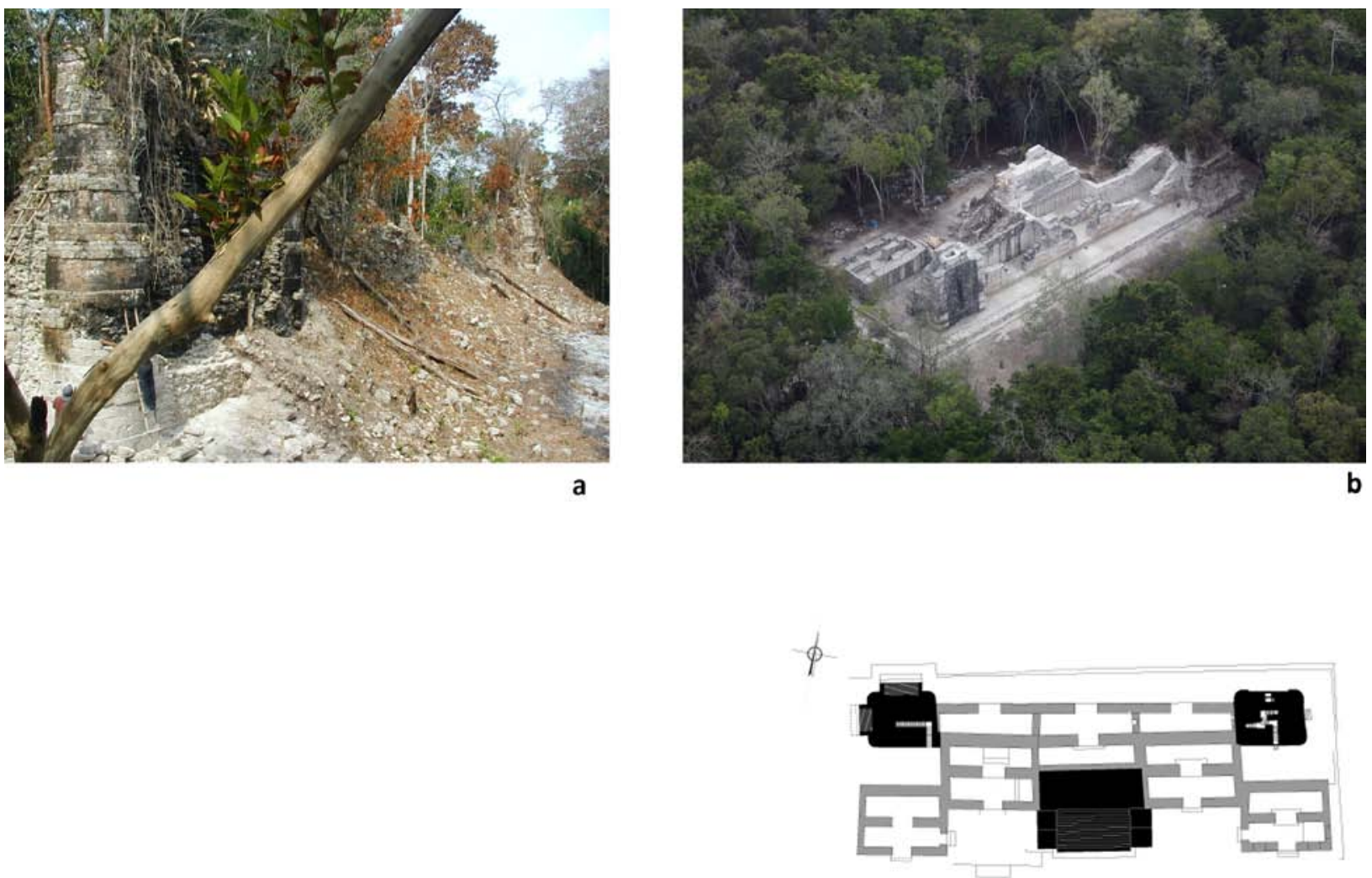

Figura 3. a) Fachada norte del edificio 5N2 antes de las excavaciones. Fotografía proporcionada por Dominique Michelet. b) Vista superior del edificio $5 \mathrm{~N} 2$ después de las excavaciones y de la restauración arquitectónica. Fotografía proporcionada por Dominique Michelet c) Planta del edificio 5N2 (levantamiento Dominique Michelet, J. Damián Álvarez; digitalización Célline Gillot).

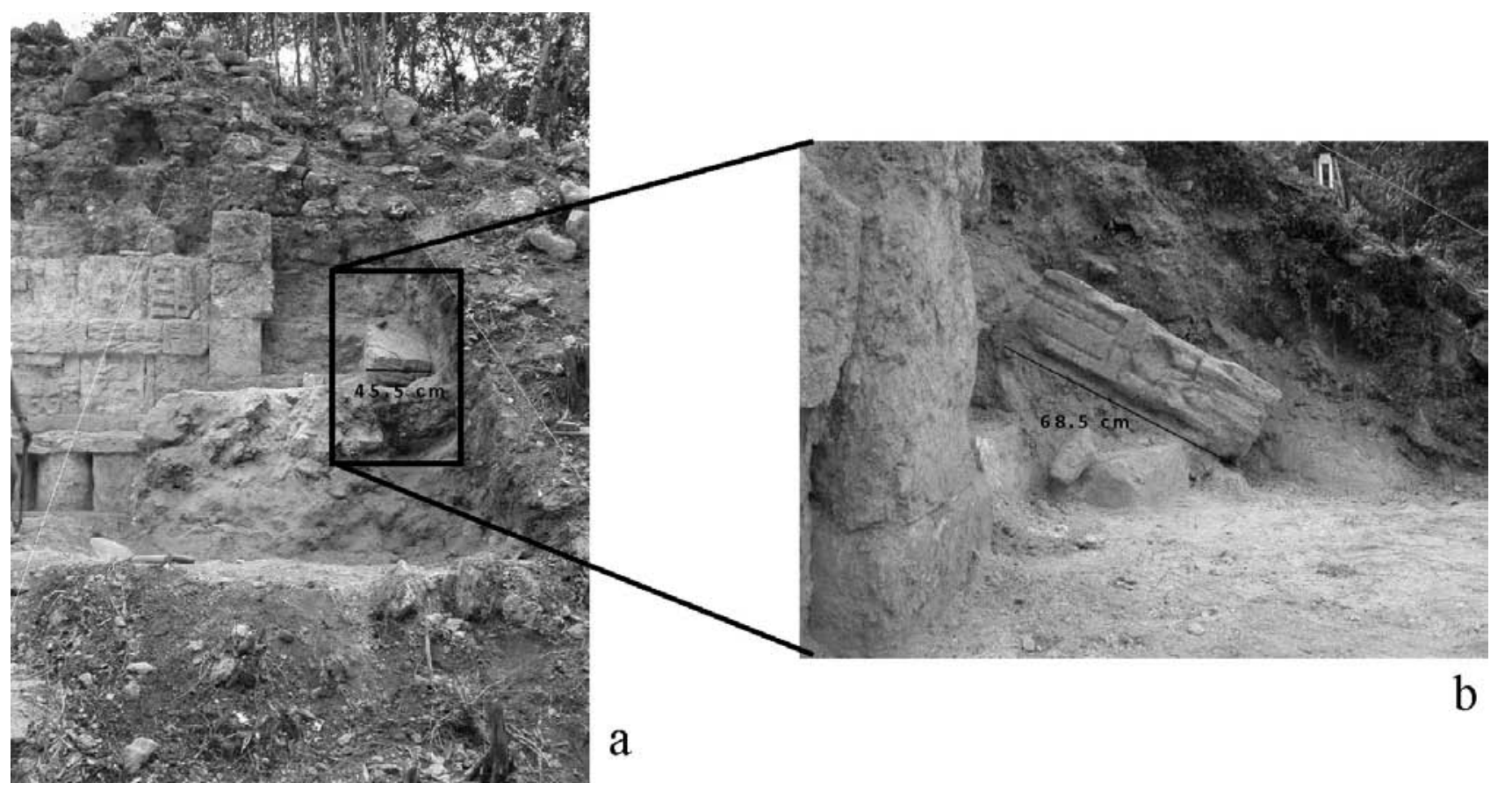

Figura 4. a) Vista frontal de la fachada norte del edificio 5N2. A la derecha de la imagen se observa una roca perteneciente a la cornisa (piedra esquinera con motivo del monstruo de la tierra) en el derrumbe, atrás se nota parte de un panel decorativo. b) En la fotografía se observa un detalle de la roca esquinera. Es de notar la capa de suelo enriquecido con humus. Fotografías de excavación proporcionadas por Dr. Dominique Michellet. 
nivel microscópico, la relación de estos con el estado de disgregación de la roca, así como los cambios mineralógicos que pudieran haberse llevado a cabo,

Así mismo se tomaron muestras para su observación en microscopio electrónico de barrido. Estas se recubrieron con oro-paladio y se observaron en un microscopio Jeol JSM6460LV (placas), en la Facultad de Medicina de la UNAM y en un Jeol JSM 6360LV (digital), en el Instutituto de Ciencias del Mar y Limnología, UNAM. Adicionalmente se realizaron análisis de Difracción de Rayos X (DRX) en el Instituto de Geología de la UNAM, para confirmar la composición mineralógica de las rocas.

\section{Resultados}

\subsection{Observaciones Macroscópicas}

Las calizas con las que se realizaron las piezas de la cornisa, presentan tipos distintos de deterioro, por ello se infiere que hay distintos tipos de caliza que se clasificaron en tres tipos de roca distintos según su estado de disgregación (Figura 5):

- No disgregada: Piedra dura, de color blanco grisáceo con una ligera tonalidad morada. Este tipo de roca presenta grades huecos en su superficie (microkarst) pero es muy dura. En general no presenta disgregación considerable del material.

- Disgregada: Piedra de color blanco brillante. Generalmente presenta pulverulencia en la mayoría de sus caras; se deshace en un polvo muy fino con textura de sascab.

- Muy disgregada: Piedra blanca rosácea-amarillenta. Este tipo de piedra presenta el mayor grado de deterioro en el contexto de enterramiento de Río Bec. Muestra una capa de material muy deteriorado y sin cementación al sustrato original que incluso es de color distinto cuando está húmedo. Existe una subdivisión dentro de la categoría:
- Rocas que se disgregan en forma de estratos bien definidos

- Rocas que se descomponen en forma de nódulos, parecido a la desintegración granular de algunas rocas.

La fragmentación de las rocas se debe a la presencia de raíces entre fragmentos causando un polvillo grisáceo y cristalino; inclusiones de pedernal de algunos centímetros cuadrados en la estructura de la caliza, causando que ésta tienda a romperse. El pedernal es más duro que la caliza y reacciona diferente ante los cambios ambientales, dilatándose y contrayéndose menos que la matriz de carbonatos de calcio. Es por ello que en las zonas aledañas al pedernal se comienzan a formar microfisuras que serán un punto inestable dentro de la estructura, por lo que se desprenderán fácilmente.

\subsection{Observaciones microscópicas}

Los resultados obtenidos de la observación con las distintas técnicas microscópicas permitieron observar rasgos primarios y secundarios.

Las rocas utilizadas para la fabricación de la cornisa son calizas sumamente puras aunque de composición heterogénea. En general presentan una matriz micrítica (Figura 6a) con oolitos (Figura 6d), estructuras fluidales (Figura 6c), turbiditas, estructuras algáceas, etc. Se pueden encontrar zonas con esparita (Figura 6a) en áreas muy localizadas que fueron formadas por procesos diagenéticos de recristalización. Además se pueden encontrar minerales autígenos como pedernal (Figura 6f), cuarzo y halita. Así mismo, se pueden encontrar elementos alogénicos como arcillas (Figura 6e) que por sus altos colores de interferencia parecen ser del tipo esmectita. Por otro lado, se encontró que una de las rocas analizadas tenía una estructura cristalina bien desarrollada, con cristales grandes romboidales, cuya forma es típica de la dolomita (Figura 6b).

Los rasgos de intemperismo observados en las muestras fueron diversos y no sólo afectaron a la matriz micrítica, sino a

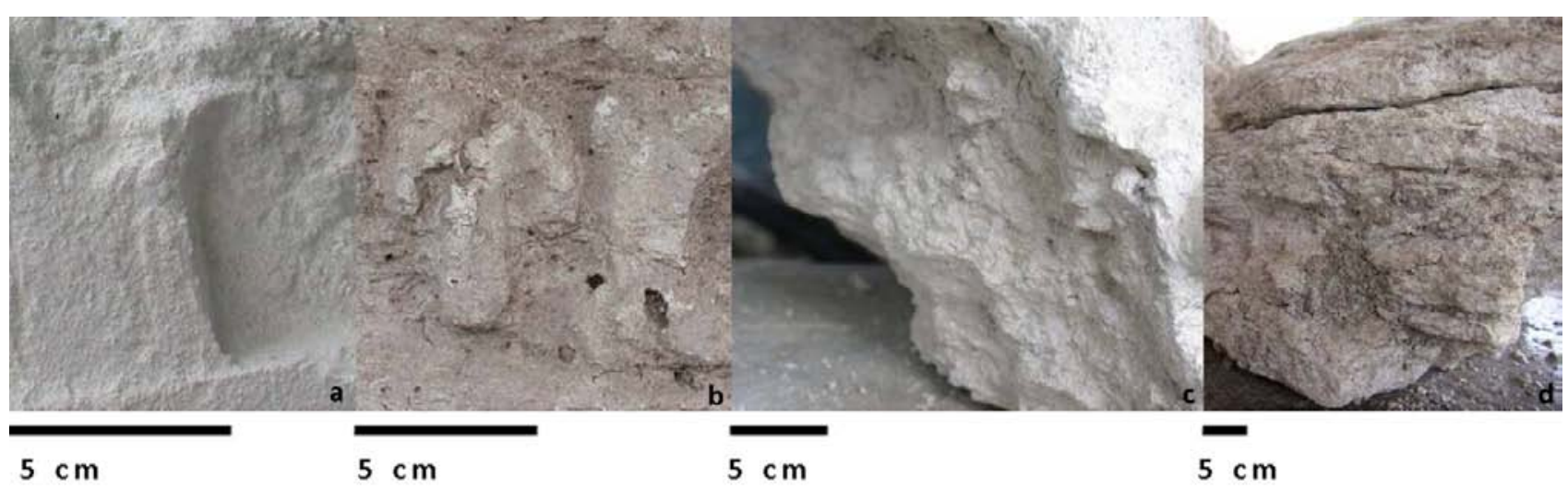

Figura 5. a) En la primera imagen se observa la piedra blanca que se deteriora en forma de polvo. b) En la segunda se ve la piedra más dura que ha perdido todo el estuco. c) En la tercera se puede ver el deterioro en forma de nódulos y en la cuarta, d) el deterioro en forma de estratos. 


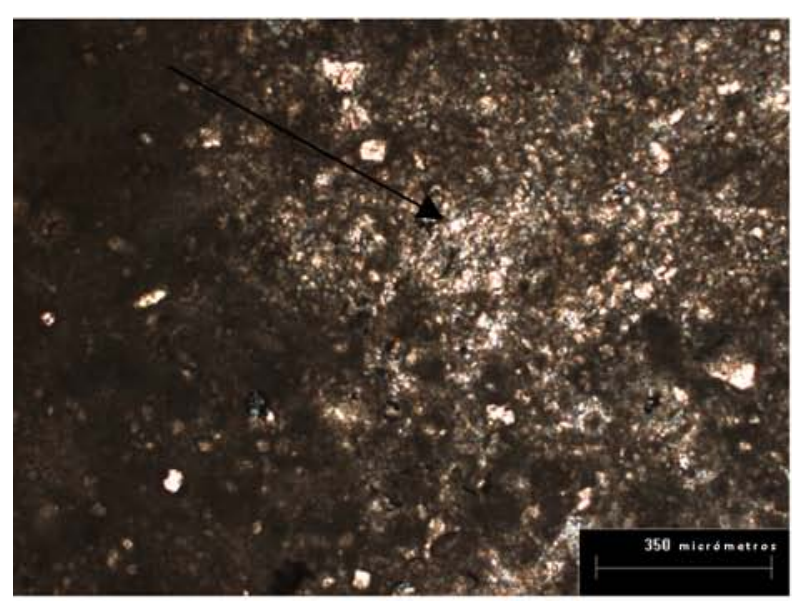

a

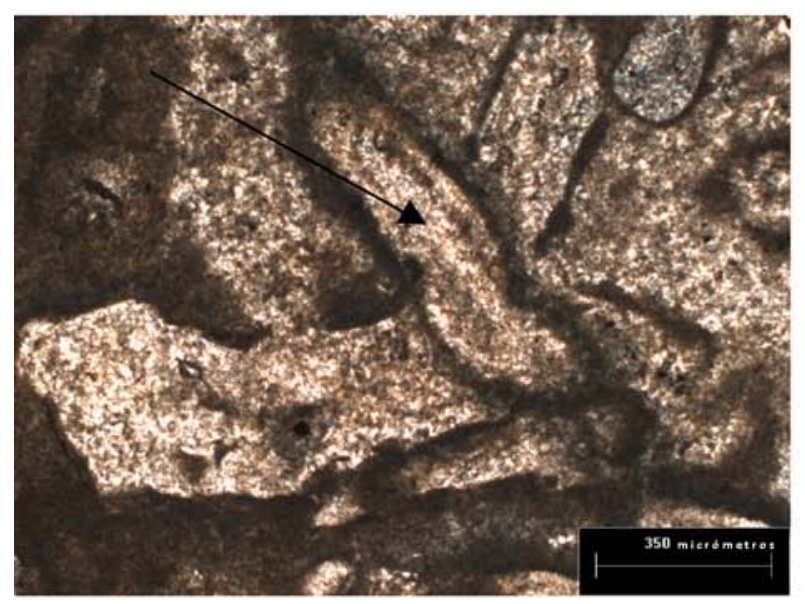

c

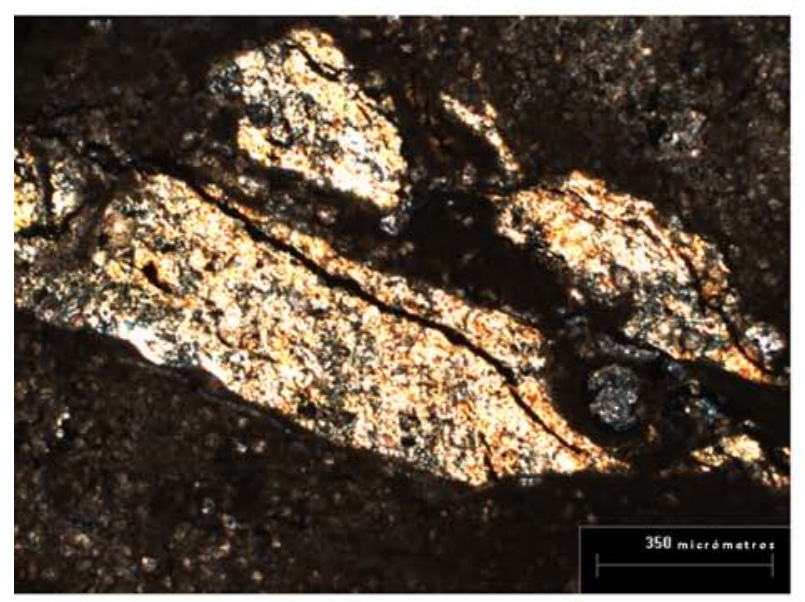

e

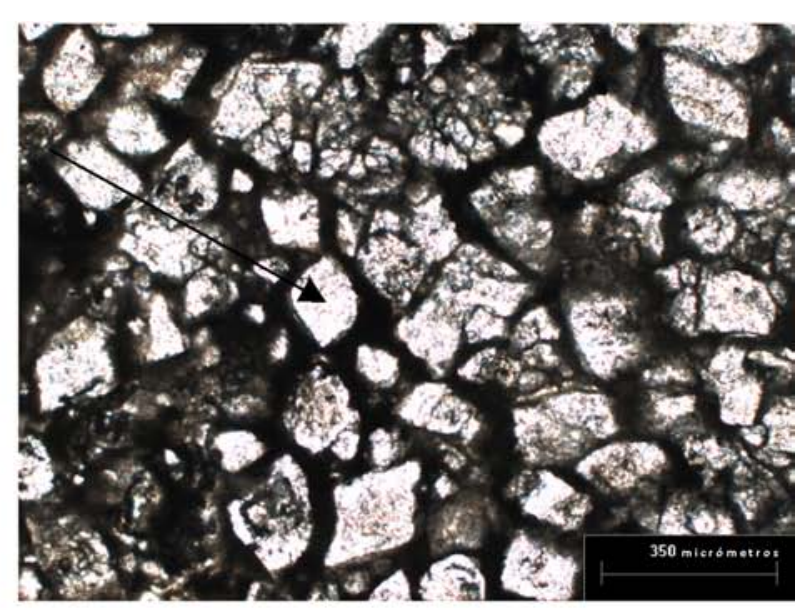

b

d

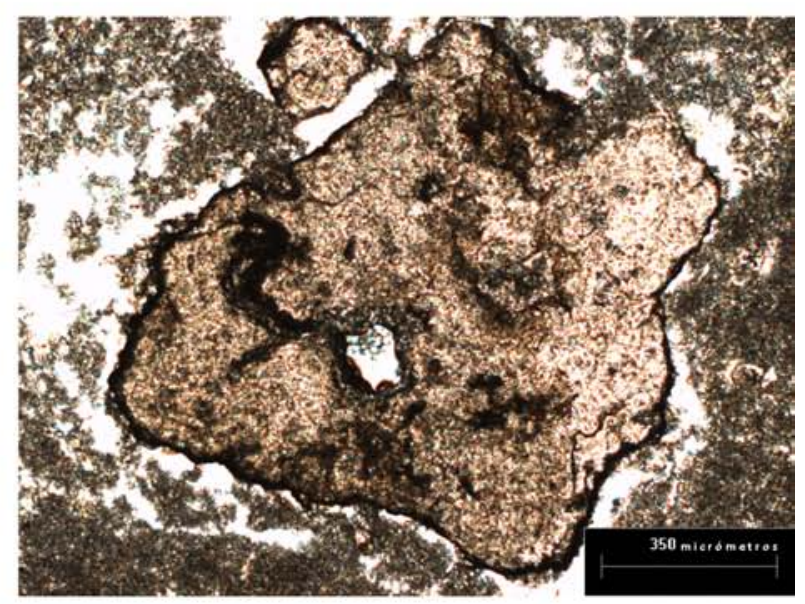

f

Figura 6. a) Micrita con formación de esparita. $\mathrm{N}+(4 \mathrm{x})$. b) Cristales con estructura bien desarrollada. $\mathrm{N}+(4 \mathrm{x}) . \mathrm{c})$ Estructuras fluidales. Ppl (4x). d) Oolitos. Ppl (4x). e) Arcillas. N+ (4x). f) Pedernal. Ppl (4x). 
otros componentes de la roca, generando efectos observables tanto microscópicamente como macroscópicamente. Los que se hallaron con mayor frecuencia fueron la falta de cementación entre granos individuales de micrita (Figura 7b) y la formación de carbonatos secundarios en forma de aguja (Figura 7a) (cristales aciculares).

La superficie de las rocas intemperizadas, se encuentra pulverulenta ya que tiene granos de micrita poco cementados al núcleo de la roca. El grado de cementación es inversamente proporcional al grado de disgregación de la roca. Además se observaron varios tipos de fisuras: unas paralelas a la superficie de la roca, en tanto que otras siguen planos de debilidad. Algunas de ellas presentan carbonatos secundarios rellenando parte del espacio vacío y formando puentes entre las dos caras de las fisuras (Figura 7c y d).

En algunos casos estas fisuras o fracturas pudieron ser causadas por la presencia de algunas de las impurezas presentes en las rocas, las cuales se comportan diferencialmente del carbonato de calcio. Las arcillas del tipo esmectita, si se hidratan aumentan su volumen,

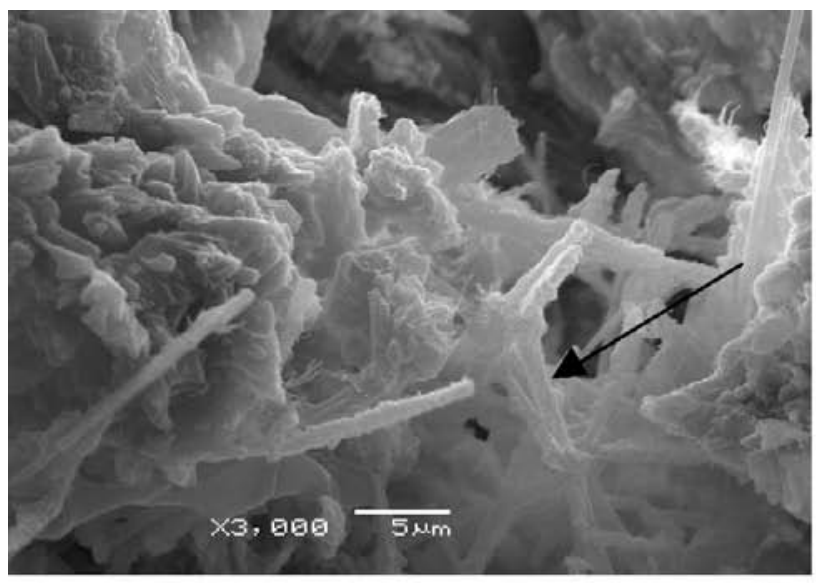

a

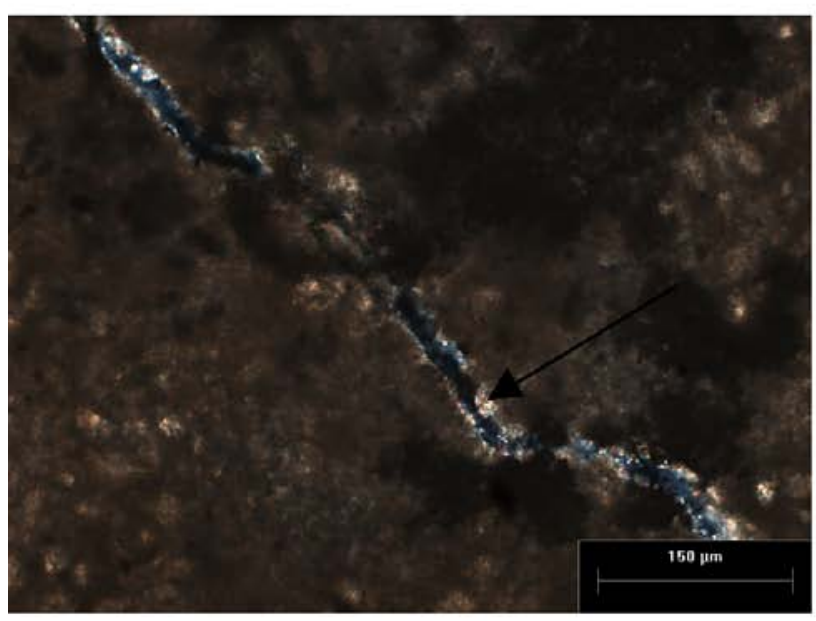

$\mathrm{C}$ propiciando zonas de debilidad en la matriz de calcita circundante por la presión ejercida. Así mismo, los fragmentos grandes de pedernal tienen un comportamiento diferencial en comparación a la calcita, además siendo un material con más dureza puede provocar fracturas en caso de que se exceda la capacidad de la micrita para soportar presiones.

Se observaron también conductos provocados por la acción de microraicillas que penetran en la roca disolviéndola, es decir, poros biogenéticos.

Por otro lado se advirtieron nódulos concéntricos de color marrón cerca de la superficie de las muestras o bandas marrones en la periferia de los poros que con luz reflejada se observaban amarillos, confirmando que había óxidos de hierro en su composición (Figura 8a).

En las láminas delgadas, los cristales aciculares, acomodados en forma caprichosa y heterogénea (Figura 8 b), se observaron constituyendo la mayor parte de la superficie de las muestras que presentaban un mayor grado de disgregación. También se formaron este tipo de cristales

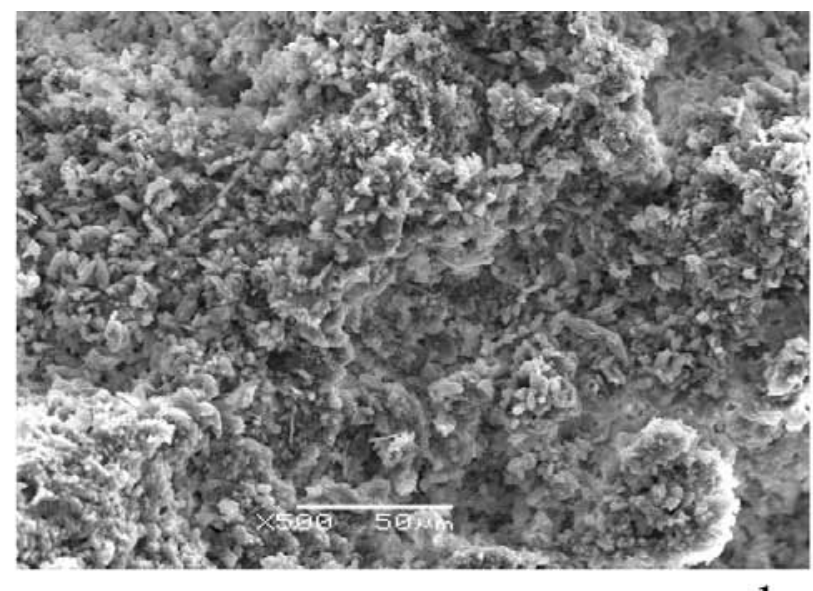

b

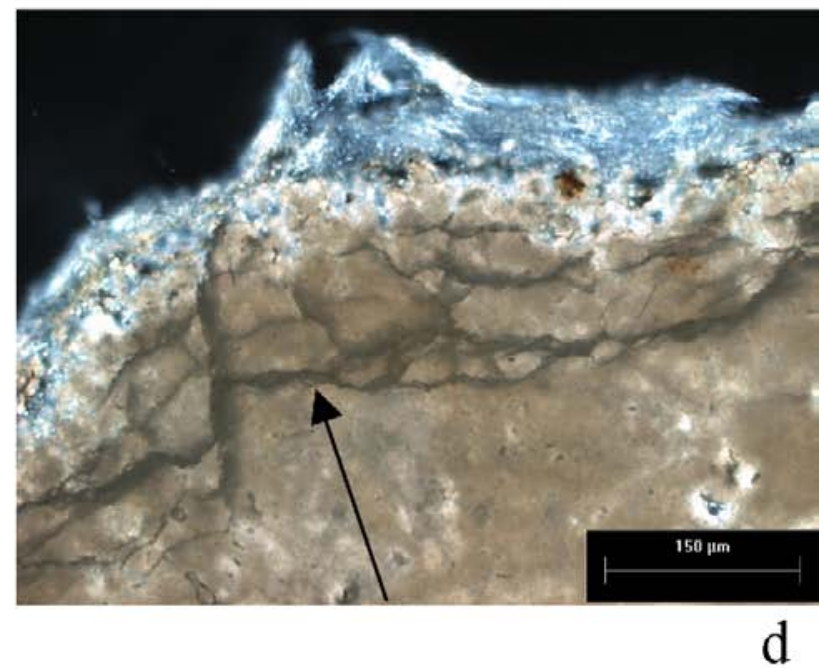

Figura 7. a) Cristales aciculares de calcita (MEB). b) falta de cohesión de cristales de micrita superficiales (MEB). c) fisura con recristalización de calcita. $\mathrm{N}+(10 \mathrm{x}) . \mathrm{d})$ Fisuras paralelas a la superficie. $\mathrm{N}+(10 \mathrm{x})$. 

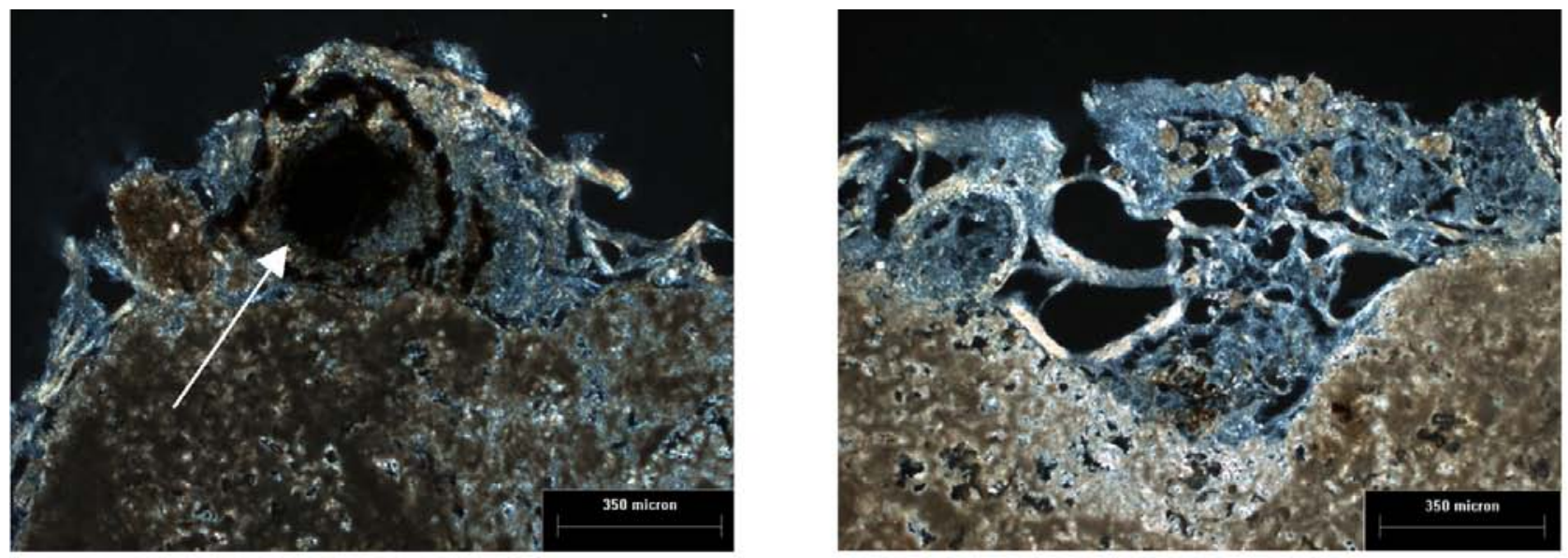

a
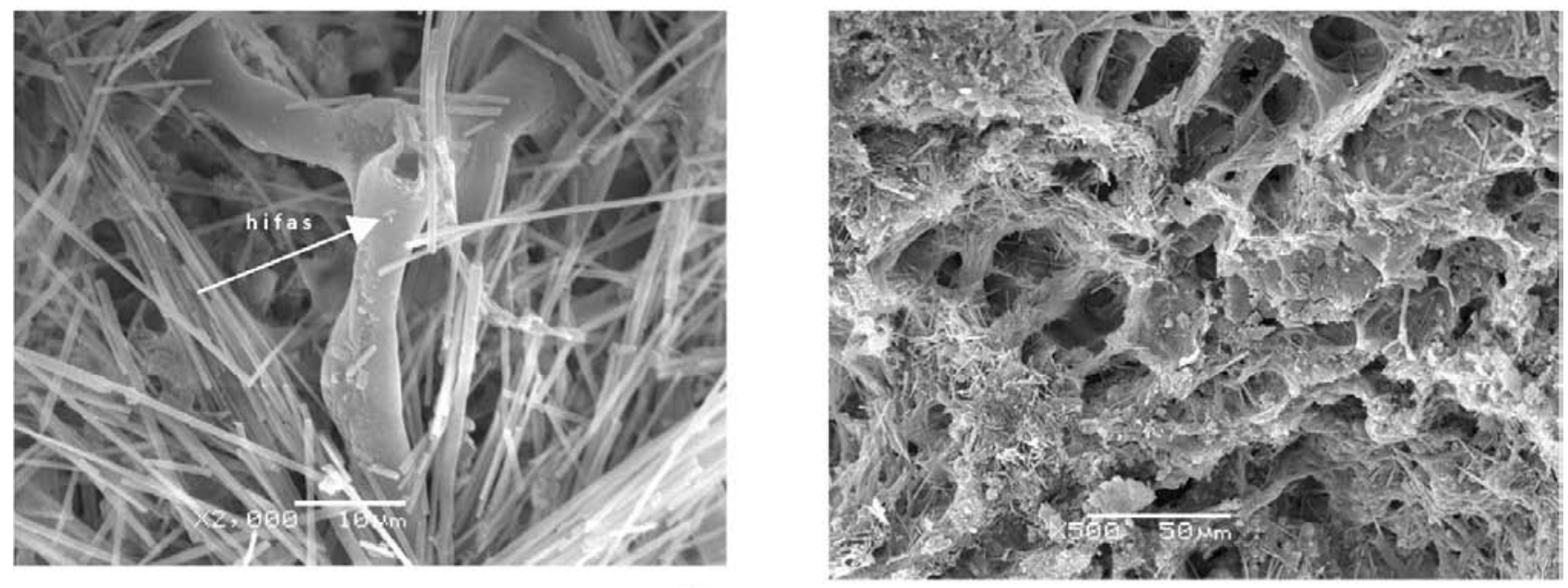

C
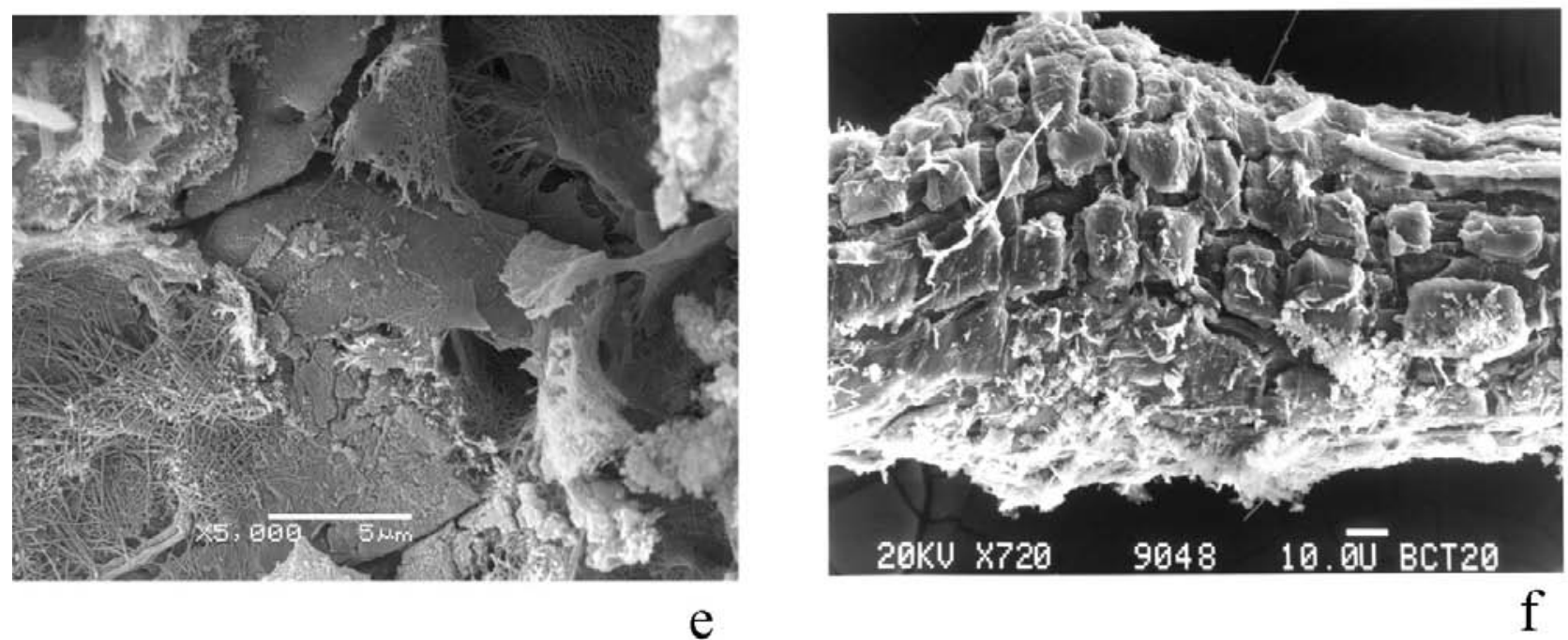

e

Figura 8. a) Nódulo concéntrico de Fe en la superficie. $\mathrm{N}+(4 \mathrm{x})$. b) Cristales aciculares acomodados heterogéneamente en la superficie de la muestra. $\mathrm{N}+$ (4x). c) Cristales aciculares en relación con hifas fúngicas, (MEB). d) Patrón en forma de "panal" provocado por la acción de raíces, (MEB). e) Detalle de la composición de las paredes de dicha estructura, (MEB). f) superficie de una raíz encontrada en las muestras, (MEB). 
en la mayoría de los poros de las rocas, en entramados heterogéneos y con poca cohesión entre sí. Con microscopía electrónica de barrido se advirtió que estos cristales no presentaban un orden específico y que están relacionados con hifas fúngicas (Figura $8 \mathrm{c}$ ).

Además los canales formados por microraicillas presentaron una micromorfología particular: cada canal esta formado por diversas celdas (tipo panal) que parecen copiar en un negativo la superficie de las raíces que les dieron origen (Figura 8f). Cada celda está formada por cristales aciculares de distintos tamaños entramados finamente (Figura 8d y 8e).

Conjuntamente se pudo comprobar la relación entre el estado de conservación de las rocas detectado macroscópicamente (no disgregada, disgregada y muy disgregada), la micromorfología y la composición mineralógica de la roca. Las rocas muy disgregadas y disgregadas no poseen diferencias esenciales en su composición mineralógica; sin embargo, las rocas muy disgregadas presentaron un mayor grado de deterioro debido a que exhibían mayor concentración y mayor variedad de efectos de intemperismo en comparación con las disgregadas.

Por otro lado, las rocas no disgregadas tienen rasgos diagenéticos que les proporcionaron una mayor dureza como una mayor conversión de micrita a esparita y un grado elevado de cristalización. Además los estudios de difracción de rayos $\mathrm{X}$ evidenciaron que una de las rocas estudiadas presentó fluorita (lo que proporciona una mayor dureza) en su composición, mientras las demás rocas estaban compuestas esencialmente por calcita.

\section{Discusión y conclusiones}

Los habitantes y escultores de Río Bec no tenían un sistema de elección para las rocas utilizadas en los elementos decorativos como la cornisa del edificio $5 \mathrm{~N} 2$ de Río Bec, distinguiendo entre las más suaves o las más duras. No obstante, una vez que tenían los bloques, el trabajo de talla sí era diferente: en las rocas suaves se perfilaba una débil preforma que era acabada y detallada con capas de estuco; por el contrario, las rocas duras tienen un mayor acabado del diseño desde la preforma tallada en roca.

Por otro lado, la roca utilizada es una caliza sumamente pura con algunas inclusiones de arcilla, pedernal, cuarzo y sílice. $\mathrm{Ni}$ en los análisis de difracción de rayos $\mathrm{X}$, ni en los estudios petrográficos se encontró la presencia de minerales con azufre, por lo que el deterioro avanzado de las rocas no se debe a la formación de sulfatos por componentes intrínsecos del material. Los sulfatos encontrados en la superficie de las rocas que conforman estos edificios provienen, posiblemente, del cemento utilizado para la restauración arquitectónica.

La lámina delgada de la roca que presentaba una desarrollada estructura cristalina de forma romboidal fue teñida con rojo alizarina para distinguir si se trataba de cristales de dolomita o calcita. La coloración de los cristales indicó que esta roca sufrió un proceso de dedolomitización, en el cual la dolomita fue sustituida por calcita pseudomorfa.

La disolución del carbonato de calcio genera los problemas de deterioro principales de las rocas de esta cornisa, ya sea por la simple acción del agua acidificada con anhídrido carbónico o por acción conjunta entre ésta y organismos biológicos como hongos y raíces. Las fisuras y fracturas encontradas en las rocas promueven la penetración del agua y otros agentes de intemperismo al interior de la roca, provocando la disolución de material a profundidades mayores. No obstante cuando este proceso es continuo durante un período largo, las fracturas comienzan a sellarse por la recristalización de calcita que se da al interior de la roca obstaculizando la penetración de estos agentes.

Los rasgos de intemperismo como los nódulos concéntricos y halos de hierro alrededor de poros fueron provocados por la óxido-reducción de óxidos férricos, lo que denota un ambiente de gleización en dónde las rocas estuvieron en ambientes anóxicos seguidos por ambientes con oxígeno. Esto se puede deber a la saturación del suelo por la abundante precipitación y la consecuente rápida evaporación en la época de secas.

Por otro lado, la disolución provocada por agua induce la formación de estructuras características observables a nivel macroscópico llamadas microkarsts. La posterior recristalización del $\mathrm{CaCO}_{3}$ provoca cambios micromorfológicos en la calcita convirtiéndola en cristales aciculares que no poseen cementación con el resto de la roca, lo que provoca efectos macroscópicos como pulverulencia y disgregación, lo cual es semejante a lo reportado por Becze-Deák et al. (1997) y por Khokhlova et al. (2001) para sustratos edafológicos. Estas dos autoras suponen la formación de cristales aciculares debido a la biomineralización formada por hongos, microraíces, etc. Este caso parece confirmar la correlación entre la presencia de estos agentes de bioalteración y la formación de cristales aciculares; sin embargo, la biomineralizaicón no parece ser el mecanismo de formación de los pseudomicelios, ya que el carbonato de calcio que los conforma no parece biogenético. La disolución de la calcita provocada por el agua y los agentes quelantes así como los ácidos orgánicos que excretan estos organismos, y la posterior recristalización de la calcita disuelta, parece ser el origen de estos cristales.

Es de notar que los cristales aciculares provocados por la acción de raíces y de hongos se unen en estructuras morfologícas sumamente distintas. Las raíces provocan el entramado de estos cristales en películas que forman las paredes de una estructura de celdas. Por otro lado, los hongos provocan estructuras desordenadas de cristales aciculares más largos y menos cementados.

Por otro lado, el grado de deterioro de las rocas depende de dos cosas, de las causas intrínsecas y por otro lado, de las causas extrínsecas. Las causas intrínsecas son aquellas que tiene que ver directamente con la conformación original 
del objeto. Al respecto se puede decir que la conformación micrítica de la roca provoca que por su tamaño y estructura particular tenga una amplia superficie para que los agentes de deterioro actúen; así mismo, las impurezas que presentan un comportamiento diferencial también favorecen su deterioro. Por otro lado, las rocas que presentan menos deterioro exhiben una estructura más cristalina que las hace más resistentes al intemperismo.

Las causas extrínsecas son todas aquellas que provienen del medio ambiente que rodea al objeto. En este caso el contexto arqueológico donde se hallaron las rocas tiene que ver con su estado de disgregación. Al encontrarse en la capa de destrucción bajo una capa de suelo enriquecida en humus, había gran cantidad de $\mathrm{CO}_{2}$ disponible para generar ácido carbónico, además de encontrarse una gran cantidad de microorganismos que favorecieron los procesos de deterioro químico junto con raíces y microraicillas provenientes de las plantas superiores que crecían en la cubierta edáfica. La posición de las rocas en el derrumbe también debió de influir en el grado de alteración de las piedras, ya que las encontradas en estratos superiores debieron haber estado sometidas a mayores agentes de intemperismo.

Por lo tanto, los efectos de deterioro exhibidos por las rocas dependerán tanto de la estructura primaria de la roca, así como de las condiciones ambientales a las que estuvieron expuestas. En este caso las rocas más cristalinas presentaron mucho menos efectos de intemperismo que las rocas con cristales más pequeños. La diferencia de deterioro entre las rocas micríticas se puede deber a la posición estratigráfica que ocuparon en el derrumbe.

Finalizando, es necesario concluir que cualquier solución que pretenda darse para la conservación de los edificios y elementos de decoración presentes en esta región, debe estar encaminada a disminuir la solubilidad de la roca por la acción de diversos factores de intemperismo para lograr que su "tiempo de vida" sea mayor.

\section{Agradecimientos}

Las láminas delgadas fueron financiadas con recursos del proyecto Río Bec dirigido por Dr. Dominique Michelet, Dra. Charlotte Arnauld y Dr. Philippe Nondédéo (CNRS-UMR 8096, Université Paris 1). Las fotografías de las láminas delgadas fueron tomadas por el Dr. Sergey Sedov (Instituto de Geología, UNAM). Las imágenes de microscopía electrónica de barrido fueron tomadas por la Dra. Yolanda Ornelas (Instituto de Ciencias del Mar y Limnología, UNAM) y por la Dra. Silvia Antuna (Facultad de Medicina, UNAM). Así mismo se agradece a la PhD Isabel Medina Gonzáles (CNCPC-INAH) y al Dr. Jorge Gama Castro (Instituto de Geología, UNAM) quienes dirigieron el trabajo de tesis del cual provienen la mayor cantidad de resultados y datos presentados en el artículo.

\section{Referencias}

Anrubio-Vega, E.J., 1998, Causas y efectos de deterioro de los materiales arqueológicos calcáreos del Sur de Quintana Roo y una propuesta para su conservación: México D.F., Escuela Nacional de Conservación, Restauración y Museografía, tesis de licenciatura, $207 \mathrm{p}$.

Arnauld, C., Vannière, B., Michelet, D., Lemonnier, E., Nondédéo, P., 2008, Houses, emulation and cooperation among social groups at Río Bec (resumen), en 73rd Annual meeting of the Society for American Archaeology: Vancouver, British Columbia, Canadá, Society for American Archaeology, 57.

Becze-Deák, J., Langhor, R., Verrecchia, E.P., 1997, Small scale secondary $\mathrm{CaCO} 3$ accumulations in selected sections of the European loess belt. Morphological forms and potential for paleoenvironmental reconstruction: Geoderma, 76, 221-252.

Bravo-Álvarez, H., Soto-Ayala, R., Sosa-Echeverría, R. Sánchez-Álvarez , P., 2003, Efecto de la lluvia ácida en el material constituyente de los monumentos mayas mexicanos: Ingeniería. Investigación y Tecnología, 4, 195-205.

Castro-Mora, J., 2002, Monografía Geológico-Minera del estado de Campeche: México, Consejo de Recursos Minerales, 154 p.

De los Ríos, A., Ascaso, C., 2005, Contributions of in situ microscopy to the current understanding of stone biodeterioration: International Microbiology, 8, 181-188.

De los Ríos, A., Cámara, B., García del Cura, M.A., Rico, V.J., Galván, V., Ascaso, C., 2009, Deteriorating effects of lichen and microbial colonization of carbonate building rocks in the Romanesque churches of Segovia (Spain): Science of the Total Environment, 407, 1123-1134.

Ford, D.C., Williams, P.W., 2007, Karst Hydrogeology and Geomorphology: Chichester, Sussex del Oeste, Inglaterra, Jhon Wiley \& Sons, $576 \mathrm{p}$.

García-Solís, C.A., Valencia-Pulido, S.B., 1996, Proyecto Chicanná, Campeche. Informe de trabajo-temporada julio 1996: México, Archivo de la Coordinación Nacional de Conservación y Restauración del Patrimonio Cultural, informe de trabajo, $45 \mathrm{p}$.

García-Solís, C.A., Valencia-Pulido, S.B., 1997, El deterioro de piedra en la zona arqueológica de Chicanná, Campeche y una propuesta para su conservación: México D.F., Escuela Nacional de Conservación, Restauración y Museografía, tesis de licenciatura, $214 \mathrm{p}$.

García-Vierna, V., García-Solís, C.A., Valencia-Pulido, S.B., 1997, Informe de los trabajos de conservación realizados en la Estructura II. Diagnóstico general del sitio. Zona arqueológica de Chicanná. Campeche. Octubre a Noviembre de 1996: México, Archivo de la Coordinación Nacional de Conservación y Restauración del Patrimonio Cultural. informe de trabajo, $57 \mathrm{p}$.

Gaylarde, P.M., Gaylarde, C.C., Guiamet, P.S., Gomez de Saravia, S.G., Videla, H.A., 2001, Biodeterioration of Mayan buildings at Uxmal and Tulum, Mexico: Biofouling, 17, 41- 45.

Khokhlova, O.S., Sedov, S.N., Golyeva, A.A., Khokhlova, A.A., 2001, Evolution of Chernozems in the Northern Caucasus, Russia during the second half of the Holocene: carbonate status of paleosols as a tool for paleoenvironmental reconstruction: Geoderma, 104, 115-133.

McNamara, C.J., Perry IV, T.D., Bearce, K., Hernandez-Duque, G., Mitchell, R., 2005 Measurement of limestone biodeterioration using the $\mathrm{Ca}^{2+}$ binding fluorochrome Rhod-5N: Journal of Microbiological Methods, 61, 245-50.

McNamara, CJ., Perry, T.D, Bearce, K.A., Hernandez-Duque, G., Mitchell, R., 2006, Epilithic and endolithic bacterial communities in limestone from a Maya archaeological site: Microbial Ecology, 51, 51-64.

Michelet, D., Taladoire, E., Dzul, S., Nondédéo, P., Patrios, J., Marchand, G., Arnauld, M.-C., Déodat, L., Huser, A., Becquelin, P., Pereira, G., Ortega, J., González, E., Carrillo, Ma. R., Arano, D., Galop, D., Vannière, B., Andrieu, C., 2005, Proyecto Río Bec (Campeche México). Informe de la tercera temporada, del 16 de febrero al 15 de mayo de 2004: México, Archivo Técnico del Consejo de Arqueología, Instituto Nacional de Antropología e Historia, informe de trabajo, $406 \mathrm{p}$. 
Michelet, D., Taladoire, E., Dzul, S., Andrieu, C., Nondédéo, P., Patrios, J., Vázquez, M., Lacadena, A., Marchand, G., Arnauld, M.C., Déodat, L., Lardé, S., Gillot, C., Pereira, G., Robles, A., González, E., Carrillo, M.R, Arano, D., Galop, D., Vannière, B., Heinz, C., Latsanopoulos, N. 2006, Proyecto Río Bec (Campeche México). Informe de la cuarta temporada, del 8 de febrero al 6 de mayo de 2005: México, Archivo Técnico del Consejo de Arqueología, Instituto Nacional de Antropología e Historia, informe de trabajo, $168 \mathrm{p}$.

Michelet, D., Arnauld, M.C., Nondédéo, P., Taladoire, E., Dzul, S., Andrieu, C., Déodat, L., Gillot, C., Patrios, J., Pereira, G., Hernández, J., Marchand, G., Stock, A., Vannière, B., Lemonnier, E., Heinz, C., Gonzalez, E., Carrillo, Ma. R., Jaidar, Y., Latsanopoulos, N., 2007, Proyecto Río Bec (Campeche México). Informe de la quinta temporada, del 5 de febrero al 4 de mayo de 2006: México, Archivo Técnico del Consejo de Arqueología, Instituto Nacional de Antropología e Historia, informe de trabajo, $85 \mathrm{p}$.

Michelet, D., Arnauld, M.C., Nondédéo, P., Taladoire, E., Dzul, S., Andrieu, C., Patrios, J., Lacadena, A., Cases, I, Déodat, L., Gillot, C., Pereira, G., Álvarez, J., Vannière, B., Lemonnier, E., Gonzalez, E., Carrillo, Ma. R., Jaidar, Y., Vasquez, A., Francia, G., Latsanopoulos, N., 2008, Proyecto Río Bec (Campeche México). Informe de la sexta temporada, del 4 de febrero al 3 de mayo de 2007: México, Archivo Técnico del Consejo de Arqueología, Instituto Nacional de Antropología e Historia, informe de trabajo, $154 \mathrm{p}$

Michelet, D., Nondédéo, P., Dzul, S., Patrios, J., Gillot, C., Pereira, G., Álvarez, J., Lemonnier, E., González, E., Jaidar, Y., Straulino, L., Aguirre, M., Barrientos, I., Salazar, D., Arnauld, C., Bortot, S., Hernández, J., Forné, M., 2009, Proyecto Río Bec (Campeche México). Informe de la séptima temporada, del 19 de febrero al 5 de mayo de 2008: México, Archivo Técnico del Consejo de Arqueología, Instituto Nacional de Antropología e Historia, informe de trabajo, $350 \mathrm{p}$.
Ostroumov, M., Garduño-Monroy V.H., Carreón-Nieto, H., Lozano-Santa Cruz, R., 2003, Mineralogía y geoquímica de los procesos de degradación en monumentos históricos: primer acercamiento a un caso mexicano (Morelia, Michoacán): Revista Mexicana de Ciencias Geológicas, 20, 223-232.

Vergès-Belmin, V., (ed.), 2008, Glossaire illustré sur les formes d'altération de la pierre: Champigny/Marne, France, International Council on Monuments and Sites, Comité scientifique international "Pierre" de l'ICOMOS, Monuments et Sites 15, 79 p.

Videla, H.A., Guiawet, P.S., 2001, Mechanisms of Microbial Biodeterioration of Limestone in Mayan Buildings (en línea): en Corrosion 2001: Houston, Texas, Estados Unidos de América, NACE International, publicado 2001, disponible en < http://132.235.17.4/Scanned-Papers/ Biocorrosion/NACE1996-2003MIC/NACE2001MICpapers/01250. pdf $>$ consultado 17 de julio de 2010 .

Manuscrito recibido: Junio 21, 2010

Manuscrito corregido recibido: Mayo 27, 2011.

Manuscrito aceptado: Enero 6, 2012. 